\title{
Causal Factors of Flight Delay in Nigerian Airport: A Case Study of Murtala Muhammed International Airport
}

\author{
Ayo-Agunbiade Oluwafisayo T. \\ Department of Transport Management Technology \\ Federal University of Technology Akure, Nigeria \\ E-mail: ayofisayo90@gmail.com \\ Stephens Mobolaji S. \\ Department of Transport Management Technology \\ Federal University of Technology Akure, Nigeria \\ E-mail: msstephens@futa.edu.ng
}

\begin{abstract}
Delay is a prominent event mostly experienced at the airport by both airline and passengers. Globally delay is permitted at $\mathrm{I} 5 \mathrm{mins}$ later than the scheduled time. Assessing the level of delay in the airport is a major criterion for measuring airport performance. Aircraft not adhering to schedule flight results in increased airport congestion, cancellation flight and flight delay. This study made use of primary data through well-structured questionnaires to obtain information from selected NAMA Staff at the Murtala Muhammed International Airport (MMIA). Operational delay report for a month and Airlines flight were examined for two months under the MMA2 to know the deviation of scheduled flight time from actual flight time. Descriptive Analysis, Wilcoxon Rank test, Factor Analysis and Step Wise Regression were the statistical tools deployed for this research. Findings showed that on a monthly base, $63 \%$ of the domestic traffic flows are delayed. Some factors responsible for delay were considered: aircraft damage, bad weather, aircraft maintenance, VIP movement and fueling are the major factor responsible for delay of aircraft Movement.
\end{abstract}

\section{Keywords: Flight Delay, Factor Analysis, Congestion, Scheduling.}

\section{Introduction}

Flight planning requires accurate weather forecasts, enhances safety regulations, whereby adequate or excess fuel are carried beyond the minimum needed to fly from origin to destination (Simpson, Bashroum and Carr, I965). Scheduling process is where many of the implications that stem from the earlier work come together. The scheduler allocates each aircraft to each service, taking into account: turnaround time; the minimum time needed to empty and refill an aircraft when it passes through an airport where aircraft will be overnight, as not all aircraft will necessarily be at the hub on every night of the week. With each schedule, the airline defines its daily operations and commits its resources to satisfying its customers' air travel needs. Therefore, one of the basic requirements all airlines place on the ground handling is to ensure high efficiency of handling activities, avoiding delays. This approach of a flight schedule will reduce delay and improve the operation of the airport. Jianfeng (2012) observed that a delayed air flight which might have occurred out of positive and negative circumstances tends to have resultant effects on the passengers, airlines and airport running costs and on other flights arrivals and departures. Lack of adherence to the schedule designed by airport results in increased airport costs, congestion, flight delays and cancellations will have medium and long term reduced patronage effects, fewer passenger will want to fly through such airports as well as fewer airliners will want to fly airport prone to disruptions. Some flights are also affected by reactionary delays, due to late arrival of previous flight.

Flight delays not only annoy air travelers and disrupt their schedules, but they incur costs to the airlines when flight connections are missed, or flight crews and aircraft need to be reallocated due to maintenance problems or crew duty time limits. Flight delay can have subsequent effect on those on board and the operation of the flight and other scheduled flight at an arrival and departure airport. Aircraft schedule recovery and crew re-assignment, taking into account all constraints, factors and regulations, while trying to find solutions in a few minutes. The problem is to keep the effects of disturbances as low as possible and to return to regular operations. (Mueller \& Chattigi, 2002).

Many major airports around the world have significant delay problems as a result of an imbalance between capacities and demand. Delay often results in the increase in fuel consumption of aircrafts, affects passengers getting to their destination on time (Boye, 2015). When traffic occurs in bunches or peaks, there may be delays even when the number of aircraft using the airport is less than the capacity for that peak time period. Some amount of delay arises every time two aircraft are scheduled to use 
a runway at the same time. The probability of simultaneous arrivals increases rapidly with traffic density, so that average delay per aircraft increases exponentially well before traffic levels reach capacity levels. Having considered all these, there are various factors instituting delay in airline operation such as the relationship of demand to available capacity of an airport causes delays to aircraft movements as a result of limited runway capacity.

In developing economy like Nigeria, delay experienced by passengers is a point of consideration in the development of a nation as a whole as it affects personal expenses. Developing countries need to focus on the delay of aircraft movement at their airport to ensure increased patronage by airliners.

In summary, an accurate overview of the literature related to aircraft flight scheduling and delay has been $\mathrm{x}$-ray by building upon the sections addressing this topic in the literature reviews by Mueller and Chatterji (2002), the effects of not adhering to schedules are increased airport costs, congestion, cancellation of flights and flight delay. Studies such as Mohleji (200I), Schaefer and Miller (20I I), Hansen (2002), Mueller and Chatterji (2002) and Rosen (2002)) on airport congestion have identified several factors which generate flight delays: saturation of airport capacity (including air transportation control activities), airline problems, reactionary delays, passengers and cargo, weather and other unpredictable disruptions (e.g. strikes).

This research considered the major factor(s) responsible for delay of scheduled flight by considering the capacities utilizations, runway usage, and deviations in departures and arrivals. Grigoriy (2014), opines that there is acceptable level of flight delay, which might have positive effect on the overall operation of the airport system. The study was on flight delay performance at Hartsfield Jackson Atlanta International Airport with objective of determine the delay at the airport. This research was carried out at Hartsfield Jackson Atlanta International Airport and not Muritala Mohammed Nigeria Airport Nigeria. The researchers conducted a field based qualitative research and quantitative research, based at Murtala Mohammed Airport, in other to analyse the delay of aircraft at the airport. The various possible factors responsible for delay were also addressed. For the purpose of this study the MMIA is chosen as the case study. This is because this airport serves main aviation hub in the Nigerian aviation industry for domestic and international traffic (cargo and passengers).

The aim of the paper is to analyze aircraft delay of selected airline at the airport. A case study of Muritala Muhammed International Airport, Lagos, Nigeria. To achieve this aim, the following objectives are delineated as to estimate the average rate of deviation of actual arrivals, and departures from scheduled arrivals and departures; and evaluate the factors causing delay of scheduled flights.

\section{Theoretical Framework \\ 2.I Time Space Analysis}

Time space analysis is a simple technique to assess runway and airspace capacity if the headway between aircraft is known. It is a method to ascertain the time complexity and space complexity of an algorithm. Time complexity is a measurement of how much computational time an algorithm uses as its input size changes. Analyzing algorithms in this way provides an indicator as to how quickly the runtime increases, how it does so in relation to the input and weather the algorithm is costly for small/large inputs (Trani, 2013).

\subsection{The Basic Queuing Process}

Queuing theory is concerned with the issue of waiting; it is important to note that waiting can be quite boring, hence queuing theory examines how customers (vehicles) arrive to receive service by servers which is between arrivals of vehicles, start of service, and wait in queue. The basic applications of queue are:

- Number of customers in queue L (for length);

- Time spent in queue W for (wait) (Adeniran and Kanyio, 2019).

The basic process assumed by most queuing models is the following. Customers (Passengers) requiring service are generated over time by an input source. These customers (Passengers) enter the queuing system and join a queue. At certain times, a member of the queue is selected for service by some rule known as the queue discipline. The required service is then performed for the customer by the service mechanism, after which the customer leaves the queuing system (Fredick, 200I). Queues are called infinite or finite, according to whether this number is infinite or finite.

The assumption of an infinite queue is the standard one for most queuing models, even for situations where there actually is a (relatively large) finite upper bound on the permissible number of customers, because dealing with such an upper bound would be a complicating factor in the analysis. At a high level, we can view this problem from the perspective of queuing theory. Delays are fundamentally related to one of several issues: (a) higher scheduled demand than capacity or over-scheduling (b) a larger arrival rate than scheduled, (c) a lower service rate than scheduled, or (d) a smaller number of servers than scheduled. In the context of this paper, the gates are the servers and the service rate are the rate that aircraft can be turned at the gate. For example, if an aircraft has a longer turnaround time than scheduled, this is effectively a reduction in the service rate of the gate.

The model adopted to assess this research is Queue theory, it is the process whereby customer enters a system and service is being rendered. For this research the customer is Aircraft (both passengers and freight), the input source is the gate, the queue discipline is mostly First Come First Serve, Last in last out and emergency and the size is the total number of the aircraft per day for a period of 2 months. 


\subsection{Flight Delay}

$\mathrm{Wu}$ (2005) states that flight delay is a complex phenomenon, because it can be due to problems at the origin airport, at the destination airport, or during airborne. A combination of these factors often occurs. Delays can sometimes also be attributable to airlines. Some flights are affected by reactionary delays, due to late arrival of previous flights. These reactionary delays can be aggravated by the schedule operation. Mueller and Chatterji (2002) states the flight schedules are often subjected to irregularity. Due to the tight connection among airlines resources, delays could dramatically propagate over time and space unless the proper recovery actions are taken. Even if complex, flight delays are nowadays measurable. And there exists some pattern of flight delay due to the schedule performance and airline itself $(\mathrm{Wu}, 2005)$. Flight delay might be initiated by the airline, when airplane is not field to capacity and have might resultant effect on subsequent arrivals. The delay can be attributed to the airport, when there are limited ground-handling facilities, with increase demand. Failure of an aircraft to be cleared and failure to take off within $15 \mathrm{mins}$ of scheduled timing is delay.

There are general arrival and departure delays. This usually indicates that arrival traffic is doing airborne holding or departing traffic is experiencing longer than normal taxi times or holding at the gate. These could be due to a number of reasons, including thunderstorms in the area, a high departure demand, or a runway change. In order to understand flight delay, it is useful to consider the phenomenon of scheduled delay. The simplest way of reducing delays is not to increase the speed and efficiency of the system to meet the scheduled time, but to push back the scheduled time to absorb the system delays (Bai, 2006).

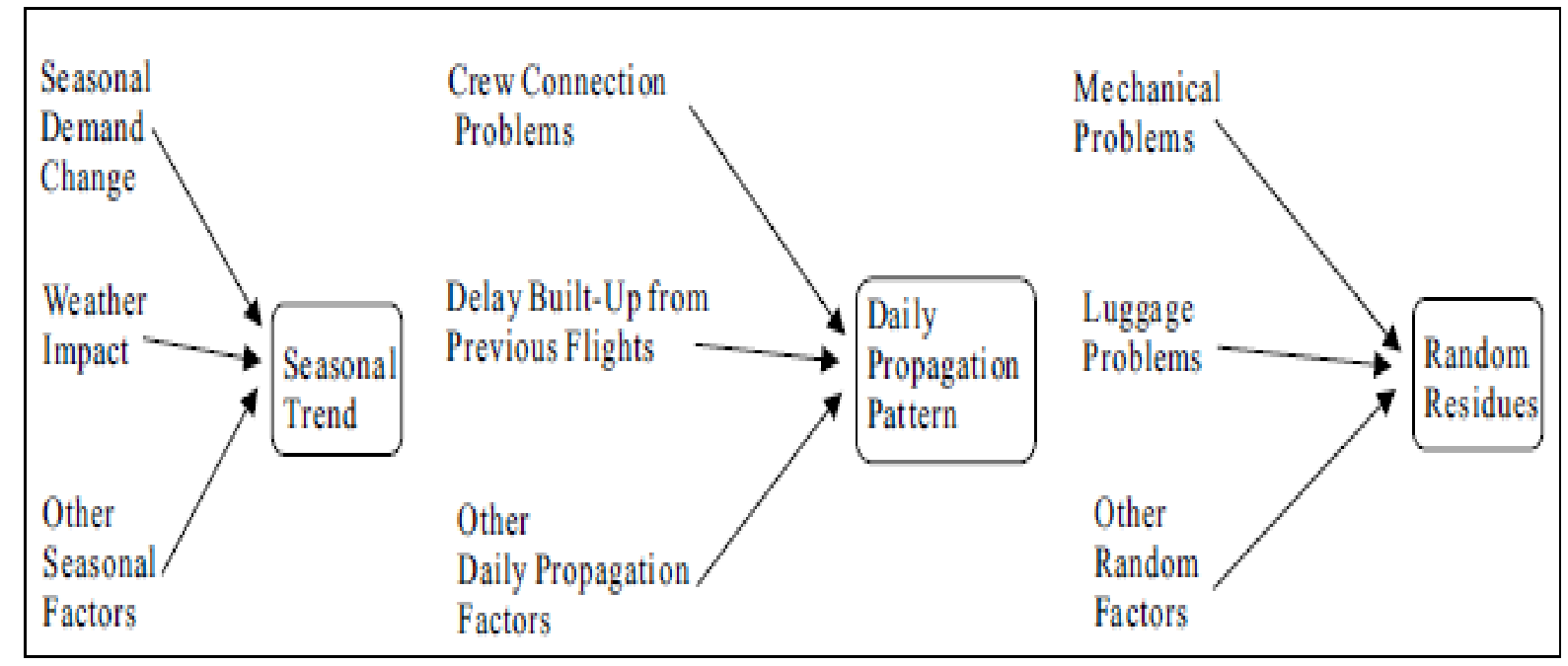

Figure I. Factors influencing departure delay

Source: Yufeng, Michael and Wolfgang (2005)

\subsection{Disruption Management}

This section of the literature review focuses on the review of some decision support tools. The following papers are approaches that aim to aid airline controllers rather than replace them with an automated decision maker. Teodorovic and Stojkovic (I995), describe an approach to the operational daily airline scheduling problem. Their research provides airline dispatchers with a decision support tool to aid their rules of thumb and enable them to make globally informed recovery decisions. Also their approach generates new airline schedules in response to disruptions provides the airline dispatcher with automatically generated recovery decisions which can be manually overridden.

\section{Method of data collection}

This study relies on secondary data sourced from the Federal Airport Authority of Nigeria (FAAN), Nigeria Airspace Management Agency (NAMA) and Nigeria Civil Aviation Authority (NCAA). The data obtained were records of flights over a period of sixteen (I6) years. To address the first objective, the installed airside capacity, and the hourly and daily traffic movements were examined. Daily traffic flow for two months and report of flight delay for a month were obtained. Daily traffic flow, for two months was gotten and report of flight delay. Descriptive Analysis, Wilcoxon Rank test, Factor Analysis and step wise regression were employed for the analysis. I 98 respondents were given questionnaire and I60 were retrieved, the sample size where obtained according to Cochran's Sample Size Formula. For the first objective, the traffic flow of aircraft for Standard at MMA2 was worked on, the Standard and Actual time of Arrival and Departure was analysed with the use of Wilcoxon, descriptive analysis, also with the aid of Excel Sheet. Secondly, several factors affecting delay where analysed through the use of factor analysis where the factors were categorized into three categories. 


\section{Results and Findings}

4.I Estimation of deviation Arrival and Departure Rate

Table I: Executive summary on international and domestic flight operations

\begin{tabular}{|c|c|c|c|c|c|c|}
\hline Routes & $\begin{array}{l}\text { Number } \\
\text { Airlines } \\
\text { Operation }\end{array}$ & & $\begin{array}{l}\text { Total Flights } \\
\text { Operated }\end{array}$ & $\begin{array}{l}\text { No. of } \\
\text { Delays }\end{array}$ & $\begin{array}{l}\text { Flight } \\
\text { Cancellations }\end{array}$ & Remarks \\
\hline $\begin{array}{l}\text { International } \\
\text { Airlines }\end{array}$ & 29 & & $\mathrm{I}, 478$ & 587 & $\mathrm{I} 4$ & $\begin{array}{l}\text { Cancelled Flights: Africa World (7), British Airways } \\
\text { (3), Air Peace (I), Arik Air (I), Asky (I), Egypt (I) } \\
\text { Air/Ramp Return: Air Peace (I) }\end{array}$ \\
\hline $\begin{array}{l}\text { Domestic } \\
\text { Airlines }\end{array}$ & 8 & & 5,168 & 3,244 & 29 & $\begin{array}{l}\text { Cancelled Flights: Arik Air (I0), Air Peace (7), } \\
\text { Overland Air (4), Medview Air (3), Aero (2), } \\
\text { Azman (2), Dana (I) } \\
\text { Air/Ramp Return: Arik Air (2), Dana Air (I) }\end{array}$ \\
\hline
\end{tabular}

Source: Nigerian Civil Aviation Authority, August 2018

For the period under review, a total number of I,478 flights were operated on international routes while 5,I68 flights were operated on domestic routes. 587 flights out of I478 were delayed for International flight and 3244 out of 5 I 68 flights were also delay, so therefore delay is evident for both.

Table 2: Flight delay occurrences

\begin{tabular}{llll}
\hline & Arrival & Departure & Total arrival and take-off \\
\hline $8-\mathrm{I} 4 / 04 / 2018$ & 65 & 58 & $\mathrm{I} 37$ \\
\hline $\mathrm{I} 5-2 \mathrm{I} / 04 / 20 \mathrm{I} 8$ & $7 \mathrm{I}$ & 70 & $\mathrm{I} 55$ \\
\hline $22-28 / 04 / 2018$ & 85 & 90 & $\mathrm{I} 96$ \\
\hline $29 / 04 / 20 \mathrm{I} 8-5 / 05 / 20 \mathrm{I} 8$ & $8 \mathrm{I}$ & 78 & $\mathrm{I} 29$ \\
\hline $6-7 / 05 / 2018$ & $\mathrm{I} 6$ & 25 & 38 \\
\hline $\mathrm{I} 3-\mathrm{I} 9 / 05 / 2018$ & 70 & 58 & $\mathrm{II} 7$ \\
\hline $20-26 / 05 / 2018$ & 83 & 58 & $\mathrm{I} 23$ \\
\hline $27-30 / 05 / 2018$ & 45 & 28 & 77 \\
\hline Total & $5 \mathrm{I} 6 / \mathrm{II} 32$ & $465 / \mathrm{II} 32$ & 972 \\
\hline Total flight Activity & 972 & & \\
\hline$\%$ Flight delay & $53.08 \%$ & $47.83 \%$ & \\
\hline
\end{tabular}

Source: Murtala Muhammed Airport Terminal 2, 201

Table 3: Wilcoxon rank test of difference between group

\begin{tabular}{llll}
\hline Group & Observe & Rank Sum & Expected \\
\hline Arrival & 8 & 75.5 & 68 \\
\hline Departure & 8 & 60.5 & 68 \\
\hline Combined & $\mathrm{I} 6$ & $\mathrm{I} 36$ & $\mathrm{I36}$ \\
\hline Wilcoxon Statistic & $0.79 \mathrm{I}$ & & \\
\hline P value & 0.4292 & & \\
\hline
\end{tabular}

Source: Authors' Compilation, 2018

\section{$H_{1}:$ ArrivalDela $\neq$ DepartureDelay}

We reject $\boldsymbol{H}_{\mathbf{0}}$ if the probability value is less than $\boldsymbol{p}=\mathbf{0 . 0 5}$.

Since the $\mathrm{P}$ value is not less than 0.05 , this gives a numerical evidence to conclude that the delay caused by flight departure is relatively the same for delay caused by flight arrival.

It can be seen that flight delay was most experienced on the $29^{\text {th }}$ April to $5^{\text {th }}$ May 2018 during the month of April to May. It has been observed that $53.08 \%$ of the total flight arrivals experienced delay within the space of two months at $15 \mathrm{mins}$ beyond the scheduled time. Table 3 shows the weekly occurrence of flight delay in the airport within the period of two months, April to May. It can be observed that flight delay is evident and occur often in arrival and departure of aircrafts. This might be due to bad weather after take-off. 


\subsection{Factors Causing Delay}

Factor analysis was conducted on the nine variables using the Principal Component Analysis method of Varimax Rotation with Kaismer Normalization. The principal components grouped the factors causing delay in both international and Local Flight by ensuring the variables were not inter-correlated and that the variables were grouped properly.

Table 4: Total Variance Explained

\begin{tabular}{|c|c|c|c|c|c|c|}
\hline \multirow[t]{2}{*}{ Component } & \multicolumn{3}{|c|}{ Initial Eigenvalues } & \multicolumn{3}{|c|}{ Extraction Sums of Squared Loadings } \\
\hline & Total & $\%$ of Variance & Cumulative \% & Total & $\%$ of Variance & Cumulative \% \\
\hline $\mathrm{I}$ & $4.95 \mathrm{I}$ & 55.016 & 55.016 & $4.95 \mathrm{I}$ & 55.016 & 55.016 \\
\hline 2 & 1.305 & $\mathrm{I} 4.502$ & 69.518 & 1.305 & $\mathrm{I} 4.502$ & 69.518 \\
\hline 3 & I.OI I & II.237 & 80.754 & I.OI I & I I.237 & 80.754 \\
\hline 4 & .804 & 8.932 & 89.686 & & & \\
\hline 5 & .439 & 4.875 & $94.56 \mathrm{I}$ & & & \\
\hline 6 & .189 & 2.103 & 96.664 & & & \\
\hline 7 & .134 & 1.486 & 98.150 & & & \\
\hline 8 &. $\mathrm{I} 2 \mathrm{I}$ & $\mathrm{I} .34 \mathrm{I}$ & 99.492 & & & \\
\hline 9 & .046 & .508 & 100.000 & & & \\
\hline
\end{tabular}

Source: Authors' Compilation, 2018

Table 4. shows the variance in flight delay accounted for by the first three principal components, extracted by principal component method using SPSS. It can be seen that about $81 \%$ variation causing flight delay was accounted for by three components. About 19\% of variation was accounted for by the remaining six components. The initial Eigen values are flight delay variations accounted for by the entire components, while the Extraction loadings are those variation accounted for by the factors extracted.

Table 5: KMO and Bartlett's Test

\begin{tabular}{lll}
\hline Kaiser-Meyer-Olkin Measure of Sampling Adequacy. & $.69 \mathrm{I}$ \\
\hline Bartlett's Test of Sphericity & Approx. Chi-Square & 395.315 \\
\cline { 2 - 3 } & Df & 36 \\
\cline { 2 - 3 } & Sig. & .000 \\
\hline
\end{tabular}

Source: Authors' Compilation, 2018

Only factors with Eigen values equal to or greater than I were considered as significant. The Eigen value of a factor represents the amount of the total variance explained by that factor. The results lead to three categories for the factors causing delay.

These factors that causes delay can be attributed to Aircraft course as component one, processing factor as component two and customer factor as component three.

We can generally conclude from the study that delay is evident in the airport and may be as a result from the airplane maintenance, delay due to customer arrival or attitude and the method of processing information.

\subsection{Step Wise Regression}

Table 6: Step wise Regression

\begin{tabular}{|c|c|c|c|c|}
\hline \multicolumn{5}{|c|}{ Model Summary } \\
\hline Model & $\mathrm{R}$ & R Square & Adjusted R Square & Std. Error of the Estimate \\
\hline $\mathrm{I}$ & $.379^{a}$ & .143 & $.08 \mathrm{I}$ & .727 \\
\hline 2 & $.378^{\mathrm{b}}$ & .143 & .088 & .724 \\
\hline 3 & $.378^{c}$ & .143 & .095 & .722 \\
\hline 4 & $.370^{\mathrm{d}}$ & .137 & .096 & $.72 \mathrm{I}$ \\
\hline 5 & $.36 \mathrm{I}^{\mathrm{e}}$ &. $\mathrm{I3I}$ & .097 & .721 \\
\hline 6 & $.353^{\mathrm{f}}$ & .124 & .097 & .721 \\
\hline
\end{tabular}

From table 6, above where the analysis of factor causing delay is represented. Factors with little or no effect are baggage handling, aircraft fueling, VIP movement, congestion of airspace and flight documentation. The factor retained by the analysis has the most important factors are Aircraft damage, bad weather, aircraft maintenance and late boarding. 


\section{Conclusion}

The delay experienced by aircraft out of every schedule is high, because most aircraft don't takeoff at the scheduled time which might be as a result of disruption. Aircraft damage, Bad weather, aircraft Maintenance, Aircraft fuelling, Congestion of the Airspace, Flight Documentation, Late Boarding, Baggage handling and VIP movement with the aid of Factor Analysis these factors were categorized into 3 components; Aircraft causes, Processing and Customer Factor which implies that the first was noted to be the major cause of delay. In addition, all contingencies must be incorporated into the schedule plan to give allowances for all forms of disruptions.

The research recommends that Schedule disruption has impact on the turnaround operation considering the effects on the overall performance of Airport, Gates and Slots restriction, Operational restriction, Airports Restrictions and other factors make planning difficult but they must be considered in the process. Airlines should be realistic in their flight planning/schedules. Airlines should develop responsive crisis management systems and file their Operation Disruption Manuals with NCAA as required by law. Airlines should also adhere to the Nigerian Civil Aviation Regulations and Passengers Bill of Rights in their dealings with passengers. This will motivate Passengers, by getting value for their money.

Considering the factors causing delay, the resultant effect can be on passengers, consideration should be given in case of missed connection flight, so airlines to ensure they provide right to care to passengers in times of delays/cancellations.

\section{References}

Adeniran, A. O., and Kanyio, O. A. (2019). Quantitative model of single-server queue System. Indian Journal of Engineering, I6, I77-I83.

Ayantoyinbo, B. (2015). Preferences for nigerian domestic passenger airline industry: a conjoint analysis. Journal of academia.

Mike, H. (2008). The air transport system. England woohhead publishing limited.

Mueller E.R and G. B. Chatterji. . (2002). Analysis of aircraft arrival and departure delay characteristics. Aiaa's aircraft technology, integration, and operations (atio), los angeles, california.

Stephens, M. S., and Ukpere, W. I. (20II). Airport capacity utilization in nigeria: a performance and efficiency analysis. African journal of business management, pp. II I04-I I I I5.

Mohleji, S. (200I). Terminal airspace/airport congestion problems in us and fms/rnav applications to reduce delays. The mitre corporation, 9-IO.

Schaefer L, M. D. (20II). Flight delay propagation analysis with the detailed policy assessment tool. Proceedings of the 2001 ieee systems, man and cybernetics conference.

Hansen, M. (2002). Micro-level analysis of airport delay externalities using deterministic queuing models: .a case study . . Journal of air transport management, 8 (2):73-87.

Jianfeng, John F. Shortley; Juan wangz and Lance sherry. (2012). Analysis of gate-waiting delays at major us airports. Center for air transportation systems research, george mason university, fairfax, va, 22030, usa.

Grigoriy, Y., Richard, S., Denis, C., John, F., Damon, L., \& Manoj. (20I4). Flight delay performance at hartsfield-jackson atlanta international. Journal of airline and airport management, 78-95.

Trani, A. A. (2003). Review of airport runway capacity. Airport capcity .

$\mathrm{Wu}, \mathrm{C}$. (2005). Inherent delays and operational reliability of airline schedules . Journal of air transport management, volume II, issue 4, pages 273-282.

Yufeng, T., Michael, B., \& Wolfgang, J. (2005). Estimating flight departure delay distributions a statistical approach with longterm trend and short-term pattern. Robert h. Smith school research paper no. Rhs 06-034.

Yuqiong., B. (200I). Analysis of aircraft arrival delay and airport on-time performance. . Huazhong university of science and technology, china, I-I I9.

\section{Copyrights}

Copyright for this article is retained by the author(s), with first publication rights granted to the journal. This is an open-access article distributed under the terms and conditions of the Creative Commons Attribution license (http://creativecommons.org/licenses/by/4.0/). 